\title{
A Biomimetic of Endogenous Tissue Inhibitors of Metalloproteinases: Inhibition Mechanism and Contribution of Composition, Polymer Size and Shape to the Inhibitory Effect \\ Supporting information
}

Masahiko Nakamoto, †[a] Teresa Escalante,[b] José M Gutiérrez,[b] and Kenneth J Shea *[a]

[a] Department of Chemistry, University of California, Irvine, Irvine, California 92697, USA

[b] Instituto Clodomiro Picado, Facultad de Microbiología, Universidad de Costa Rica, San José, 11501, Costa Rica

†Present address: Department of Applied Chemistry, Graduate School of Engineering, Osaka University, Suita, Osaka 565-0871, Japan

Corresponding Author

* Kenneth J Shea

Email: kjshea@uci.edu

Table of contents

1. Materials

2. Protein purification

3. Synthesis of monomers

4. Synthesis of polymers

5. Synthesis of crosslinked polymer nanoparticle

6. Enzyme inhibition assay

\section{Materials}


The following materials were obtained from commercial sources. $\mathrm{N}$-isopropylacrylamide (NIPAm), acrylic acid (AAc), 6-aminohexanoic acid, L-phenylalanine, L-phenylalanine methyl ester, methacryloyl chloride, azobisisobutyronitrile (AIBN), 2(dodecylthiocarbonothioylthio)-2-methylpropionic acid, sodium dodecyl sulfate (SDS), ammonium persulfate (APS), $N, N, N^{\prime}, N^{\prime}$-Tetramethylethylenediamine (TEMED), Dulbecco's phosphate buffered saline and Crotalus atrox venom were obtained from Sigma Aldrich. $N, N^{\prime}$-methylenebisacrylamide (BIS) was from Fluka. Acryloyl chloride was obtained from Alfa aesar Inc. Echis ocellatus venom was obtained from LATOXAN Inc. NIPAm was recrystallized from hexanes and benzene. Water used in polymerization was purified using a Barnstead Nanopure Diamond ${ }^{\mathrm{TM}}$ system. 12-14 kDa MWCO cellulose membranes were purchased from Fisher bland, Inc.

\section{Protein purification}

BaP1 was isolated from a venom pool collected from adult specimens of Bothrops asper of the Pacific region of Costa Rica. After extraction, venom was lyophilized and stored at $20^{\circ} \mathrm{C}$. BaP1 was purified following established methods. ${ }^{42}$ Briefly, initial purification was done via ion exchange chromatography on a CM Sephadex C-25 column (Pharmacia), followed by an affinity chromatography on AffiGel Blue column material (Bio-Rad). After BaP1 was judged to be pure by SDS-PAGE, it was lyophilized. For crystallization experiments, lyophilized BaP1 was diluted in buffer $\mathrm{A}$ [15 mM Tris- $\mathrm{HCl}(\mathrm{pH} \mathrm{8.0)}$ and 200 mM sodium chloride] and loaded onto a Superdex-200 26/60 column (Amersham Biosciences) preequilibrated with buffer $\mathrm{A}$.

\section{Synthesis of monomers}

Procedures for the synthesis of monomers THP-PHX, PHX and APhe are described in reference 27 .

\section{Polymer synthesis}


Co-monomers, initiator and chain transfer agent were dissolved in $1 \mathrm{~mL}$ DMF (total monomer concentration was $500 \mathrm{mM}$ ). The solution in a glass tube was degassed by nitrogen bubbling at $-20^{\circ} \mathrm{C}$ for $30 \mathrm{~min}$. The solution was heated to $70^{\circ} \mathrm{C}$ and the reaction was conducted for 48 hours under nitrogen atmosphere. After the reaction was stopped by cooling and exposure to the air, the conversion rate of each monomer was obtained from ${ }^{1} \mathrm{H}-\mathrm{NMR}$. The polymer was purified by the precipitation in an excess volume of cooled diethyl ether twice. The yield of polymers was determined by measuring the weight of purified polymers. The volume averaged hydrodynamic diameter of polymers in PBS at $37^{\circ} \mathrm{C}$ by the dynamic light scattering (DLS, Figure S2). The molecular weight and poly-dispersity index (Pdl) were obtained from gel permeation chromatography (GPC) obtained on an Agilent 1100 SEC system using a PLGel Mixed-C column from Polymer Labs (Amherst, MA), using DMF containing $10 \mathrm{mM} \mathrm{LiBr}$ and polystyrene as an elutant and standard, respectively. The deprotection of THP groups was carried out in the acidic condition (100 mM HCl in DMF/water = 70/30) at r.t. for 24 hours. The deprotection (>90\%) was confirmed from ${ }^{1} \mathrm{H} \mathrm{NMR} .{ }^{27}$ The deprotected polymer was precipitated in twice in an excess volume of cooled diethyl ether (Figure S1). Polymerization conditions and characterization are shown in table S1.

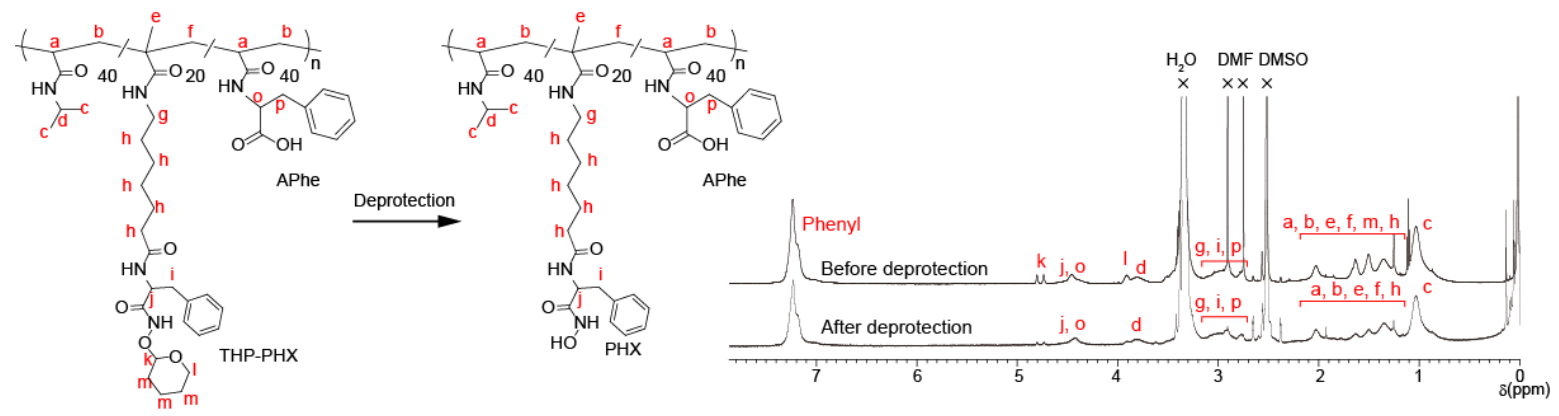

Figure $\mathrm{S} 1.500 \mathrm{MHz}{ }^{1} \mathrm{H}-\mathrm{NMR}$ spectrum of LP4 in d6-DMSO at r.t. 


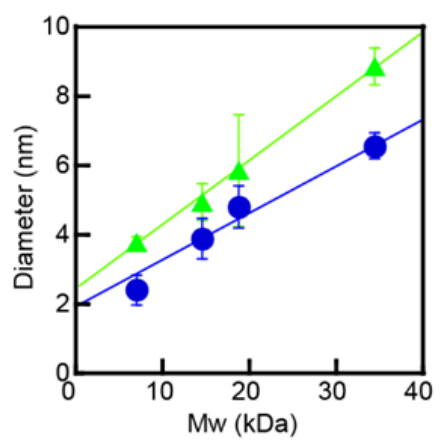

Figure S2. Volume averaged hydrodynamic diameter of LPs in PBS at $37^{\circ} \mathrm{C}$ (blue) or in DMF at $25^{\circ} \mathrm{C}$ (green) as a function of the molecular weight.

Table S1. Synthesis and characterization of RAFT polymers

\begin{tabular}{|c|c|c|c|c|c|c|c|c|c|c|c|c|c|c|}
\hline & \multicolumn{6}{|c|}{ Feed (mM) } & \multicolumn{4}{|c|}{ Conversion (\%) } & \multirow{2}{*}{$\begin{array}{l}\text { Yield } \\
\text { (\%) }\end{array}$} & \multirow[b]{2}{*}{$\begin{array}{l}\text { MW } \\
\text { (kDa) }\end{array}$} & \multirow[b]{2}{*}{ PdI } & \multirow[b]{2}{*}{$\begin{array}{l}\text { Diameter } \\
(\mathrm{nm})\end{array}$} \\
\hline & NIPAm & $\begin{array}{l}\text { THP- } \\
\text { PHX }\end{array}$ & APhe & AAC & CTA & AIBN & NIPAm & $\begin{array}{l}\text { THP- } \\
\text { PHX }\end{array}$ & APhe & AAC & & & & \\
\hline LP1 & 475 & 0 & 0 & 25 & 2 & 1.0 & 85 & - & - & 92 & 79 & 27.5 & 1.52 & $6.8 \pm 0.8$ \\
\hline LP2 & 375 & 100 & 0 & 25 & 2 & 1.0 & 86 & 82 & - & 88 & 80 & 31.2 & 1.49 & $7.1 \pm 1.2$ \\
\hline LP3 & 300 & 0 & 200 & 0 & 2 & 1.0 & 83 & - & 85 & - & 79 & 21.5 & 1.32 & $5.8 \pm 0.5$ \\
\hline LP4 & 200 & 100 & 200 & 0 & 2 & 1.0 & 70 & 71 & 70 & - & 68 & 34.5 & 1.49 & $5.9 \pm 0.2$ \\
\hline LP5 & 200 & 100 & 200 & 0 & 5 & 2.5 & 74 & 74 & 73 & - & 65 & 18.8 & 1.42 & $4.5 \pm 0.1$ \\
\hline LP6 & 200 & 100 & 200 & 0 & 10 & 5.0 & 92 & 93 & $>95$ & - & 89 & 14.6 & 1.46 & $3.4 \pm 0.5$ \\
\hline LP7 & 200 & 100 & 200 & 0 & 25 & 12.5 & $>95$ & $>95$ & $>95$ & - & 83 & 7.0 & 1.50 & $2.0 \pm 0.3$ \\
\hline
\end{tabular}

\section{Synthesis of crosslinked polymer nanoparticle}

Co-monomers (38\% NIPAm, 2\% BIS, 20\% THP-PHX and 40\% APhe) and 1 mM SDS were dissolved in $30 \mathrm{~mL}$ of water (total monomer concentration was $12.65 \mathrm{mM}$ ). THP-PHX was dissolved in 15 vol\% acetone and added into the solution. Nitrogen was bubbled through the reaction mixture at r.t. for $30 \mathrm{~min}$. Following the addition of initiator (20 mM APS and $20 \mathrm{mM}$ TEMED), the polymerization was carried out at $40^{\circ} \mathrm{C}$ for $3 \mathrm{~h}$ under a nitrogen atmosphere. The polymerized solution was purified by dialysis against an excess amount of water (changed more than 2 times a day) for 4 days. The yield of NPs was determined by measuring the weight of NPs obtained by lyophilization of the dialyzed solution. The THP protection was removed by incubating NPs solution in acidic condition $(100 \mathrm{mM} \mathrm{HCl})$ in the presence of SDS (4 mM) at r.t. for 15 hours. The NP solution was neutralized and 
purified by dialysis against an excess amount of $1 \mathrm{mM} \mathrm{NaHCO}_{3}$ (2 days), $1 \mathrm{mM} \mathrm{HCl}$ (1 days) and water ( 2 days) (changed more than 3 times a day). The concentration of NPs was determined by measuring the weight of NPs obtained by lyophilization of the dialyzed solution. The deprotection was confirmed from disappearance of protons of THP groups. We also confirmed that commoners were incorporated in NPs as designed (NIPAm: APhe: $\mathrm{PHX}=\mathrm{e}: \mathrm{b}: \mathrm{c}=2: 2: 1) .{ }^{27}$ Incorporation ratio of BIS could not be determined due to low loading amount (2\%). The hydrodynamic diameter determined by DLS and yield were $124 \pm 4 \mathrm{~nm}$ and $60 \%$, respectively.

\section{Enzyme inhibition assay}

\section{Evaluation of enzyme inhibitory effect}

The mixture of polymer $(1 \mathrm{mg} / \mathrm{mL})$ and BaPI $(2 \mu \mathrm{M})$, Crotalus atrox venom $(0.1 \mathrm{mg} / \mathrm{mL})$ or Echis ocellatus venom $(0.1 \mathrm{mg} / \mathrm{mL})$ in PBS (pH 7.5, $10 \mathrm{mM}$ phosphate containing $137 \mathrm{mM}$ $\mathrm{NaCl}$ and $3 \mathrm{mM} \mathrm{KCl}$ ) was incubated at $37^{\circ} \mathrm{C}$ for $30 \mathrm{~min} .100 \mu \mathrm{L}$ of azocasein $(10 \mathrm{mg} / \mathrm{L}$ in PBS) was added to $100 \mu \mathrm{L}$ of polymer-venom mixture and incubated at $37^{\circ} \mathrm{C}$ for $90 \mathrm{~min}$. After stopping the reaction with $200 \mu \mathrm{L}$ of $5 \mathrm{wt} \%$ trichloroacetic acid, followed by centrifugation ( $20 \mathrm{kG}, 10 \mathrm{~min}$ ), $50 \mu \mathrm{L}$ of supernatant was mixed with $50 \mu \mathrm{L}$ of $0.5 \mathrm{M} \mathrm{NaOH}$, and the absorbance at $450 \mathrm{~nm}$ was recorded. Inhibition (\%) was obtained from the equation (1) using $1 \mathrm{mM}$ EDTA as a positive control. PBS buffer with venom alone was utilized as a negative control.

$$
\text { Inhibition }(\%)=100 \times \frac{\left(\text { Absorbance }_{\text {buffer }}-\text { Absorbance }\right)}{\left(\text { Absorbance }_{\text {buffer }}-\text { Absorbance }_{E D T A}\right)}
$$

The inhibition (\%) by various concentration of polymers $(0.02-1.4 \mathrm{mg} / \mathrm{mL})$ was evaluated by the azocasein assay as mentioned above. $I C_{50}$ was obtained from curve fitting using equation (2).

$$
\text { Inhibition }(\%)=\frac{100}{1+\left(\frac{\mathrm{IC}_{50}}{[\text { polymer }]}\right)^{n}}
$$

